\title{
A contribution to Dongodytes (s. str.) Deuve, 1993 (Coleoptera, Carabidae, Trechinae)
}

\author{
Pingjing Yang', Sunbin Huang', Mingyi Tian' \\ I Department of Entomology, College of Agriculture, South China Agricultural University, Wushan, \\ Guangzhou, Guangdong, 510640, China \\ Corresponding author: Mingyi Tian (mytian@scau.edu.cn)
}

Academic editor: A. Casale | Received 15 April 2018 | Accepted 1 June 2018 | Published 6 July 2018

http://zoobank.org/3EFCD8DC-4910-46D1-8C59-6B13105AD17D

Citation: Yang P, Huang S, Tian M (2018) A contribution to Dongodytes (s. str.) Deuve, 1993 (Coleoptera, Carabidae, Trechinae). ZooKeys 772: 129-140. https://doi.org/10.3897/zookeys.772.25803

\begin{abstract}
The hypogean genus Dongodytes Deuve, 1993, one of the most cave-adapted genera of ground beetles, is distributed in northern Guangxi, ranging from Mashan through Du'an, Bama, and Fengshan to Tian'e. Review of nominate subgenus Dongodytes Deuve, 1993, with new records for D. fowleri Deuve, 1993 and D. grandis Uéno, 1998 are provided. Meanwhile, Dongodytes tonywhitteni $\mathbf{s p . ~} \mathbf{n}$. is described from a limestone cave in Bama County. This interesting species is dedicated to the late Dr. Tony Whitten, a wellknown cave biodiversity conservationist in Asia. A key to all species of Dongodytes (s. str.) is also provided.
\end{abstract}

\section{Keywords}

aphaenopsian, cavernicolous, China, ground beetles

\section{Introduction}

One of the most important events of biospeleology in China was the discovery of the aphaenopsian beetle. During a survey of China-British Cave Exploration in 1988, a single and extremely modified beetle was discovered and collected by the English caver Simon Fowler in a limestone cave in Bama County, Northwest Guangxi Zhuang Autonomous Region. It was the first cavernicolous trechine species discovered in China and was treated as 
a new genus and species Dongodytes fowleri Deuve, 1993 (Deuve 1993). But Sinaphaenops mirabilissimus Uéno \& Wang, 1991, another aphaenopsian beetle, was reported earlier though it was discovered three years later than the former (Uéno and Wang 1991).

Uéno (1998, 2005) described two Dongodytes species: D. grandis Uéno, 1998 from the cave Yuanyang Dong in Fengshan County and D. giraffa Uéno, 2005 from the cave Bahao Dong in Tian'e County. The former is very similar to the type species Dongodytes fowleri. However, D. giraffa is very peculiar by having narrow and extremely elongated pronotum which is nearly parallel-sided throughout and bearing discal setae, evident serrated along elytral lateral margins on shoulder areas and unmodified protarsomeres in male, that it should be a member of another lineage instead of Dongodytes (s. str.).

Several years later, Tian (2011) and Tian et al. (2014) added nine species of Dongodytes from caves in Du'an-Dahua Karst. Five of them (D. deharvengi Tian, 2011, D. jinzhuensis Tian, Yin \& Huang, 2014, D. brevipenis Tian, Yin \& Huang, 2014, D. inexpectatus Tian, Yin \& Huang, 2014, and D. yaophilus Tian, Yin \& Huang, 2014) are members of subgenus Dongodytodes Tian, 2011. The other four (D. baxian Tian, 2011, D. elongatus Tian, Yin \& Huang, 2014, D. troglodytes Tian, Yin \& Huang, 2014, and D. laniTian, Yin \& Huang, 2014) were treated as members of the nominate subgenus. Indeed, the above four species are very different from Dongodytes fowleri and relative species by having a particular type of male genitalia, which is very short and stout in the median lobe of aedeagus and very large in the basal orifice (Tian et al. 2014). According our un-published results of molecular analysis, we presume that they belong to another lineage other than Dongodytes (s. str.) and will be treated in our next paper.

The aim of this short paper is to provide new records for both the known Dongodytes (s. str.) species, and to describe a new species from Bama County.

\section{Material and methods}

The beetle material for this study was collected with the naked eye using an aspirator in caves and kept in 50\% ethanol. One individual of each species was preserved in 95\% ethanol for molecular analysis. Other cave beetles used for comparing were dried and mounted specimens. All studied specimens are deposited in the insect collection of South China Agricultural University, Guangzhou, China (SCAU).

Dissections and observations were made under a Leica S8AP0 microscope. Dissected genital pieces, including the median lobe and parameres of the aedeagus, were glued onto small transparent plastic plates and pinned under the specimen. Habitus pictures were taken by means of the Keyence VHX-5000 digital microscope. Genitalia pictures were taken using the Canon EOS 40D camera connected to the Zeiss AX10 microscope, and then stacked and processed in the Adobe Photoshop CC software. Distribution maps were created by using Mapinfo software.

The length of the body was measured from the apex of the right mandible (in open position); the width of the body was taken as the maximum width of the elytra. 
Abbreviations of other measurements used in the text are as follows:

HLm length of head including mandibles, from apex of right mandible to occipital suture

HL1 length of head excluding mandibles, from front of labrum to occipital suture

HW maximum width of head

PrL length of prothorax, along the median line

PnL length of pronotum, as above

PrW maximum width of prothorax

PnW maximum width of pronotum

PfW width of pronotum at front

$\mathrm{PbW}$ width of pronotum at base

EL length of elytra, from base of scutellum to elytral apex

EW maximum width of combined elytra

\section{Taxonomy}

Genus Dongodytes Deuve, 1993

Subgenus Dongodytes (s. str.) Deuve, 1993

Dongodytes Deuve, 1993: 292; Uéno 1998: 4; Tian et al. 2014: 73

Type species. Dongodytes fowleri Deuve, 1993

Range. Northwest Guangxi (Fengshan and Bama Counties) (Fig. 1).

Dongodytes (s. str.) fowleri Deuve, 1993

Figs 1, 2, 5b, 6b

Dongodytes (s. str.) fowleri Deuve, 1993: 292; Uéno 1998: 8.

Type locality. Jiabao Dong cave, Bama County.

Material. 1 female, Bama: Jiazhuan: Xingren: Jiabao: cave Xiaoshui Dong, $24^{\circ} 19^{\prime} 39.05^{\prime \prime N} / 107^{\circ} 05^{\prime} 16.96 " E, 347 \mathrm{~m}$ in altitude, 2017-III-11, leg. Sunbin Huang, Pingjing Yang \& Dianmei Wang.

Distribution. Guangxi (Bama) (Fig. 1). Known from two caves, Jiabao Dong (Uéno, 1998) and Xiaoshui Dong. The latter is a new locality for $D$. (s. str.) fowleri. It is ca. one kilometre from Jiabao Dong, and it has a large and dry chamber near the entrance which is ca. $10 \mathrm{~m}$ high and $8 \mathrm{~m}$ wide. The single specimen was discovered in a wet place on the right side of the second chamber which is ca. $100 \mathrm{~m}$ distant from the first one. 


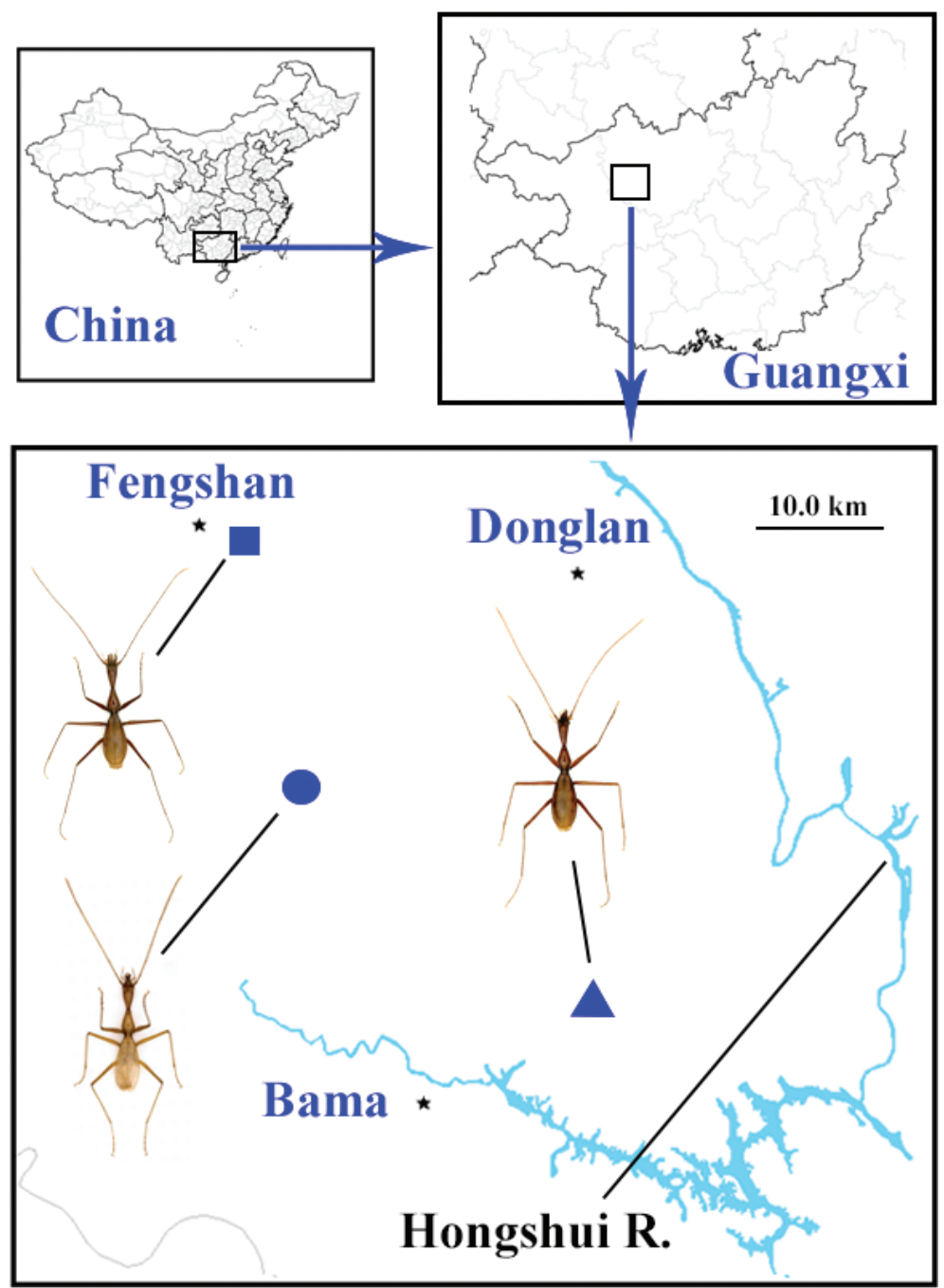

Figure I. Range of the subgenus Dongodytes (s. str.) Deuve, 1993 (square = Dongodytes (s. str.) grandis, circle $=$ Dongodytes $($ s. str.) fowleri, and triangle $=$ Dongodytes (s. str.) tonywhitteni sp. n.)

Dongodytes (s. str.) grandis Uéno, 1998

Figs 1, 3, 5c, 6c, 7c, d

Dongodytes (s. str.) grandis Uéno, 1998: 12.

Type locality. Yuanyang Dong cave, Fengshan County.

Material. 1 male, Fengshan: Fengcheng: Fenghuang: cave Yuanyang Dong, $24^{\circ} 32^{\prime} 20.76^{\prime \prime N} / 107^{\circ} 04^{\prime} 04.01^{\prime} \mathrm{E}, 691 \mathrm{~m}, 2015-\mathrm{VIII}-3$, leg. Xinhui Wang, Jujian Chen \& Mingruo Tang; 1 male, 1 female, same cave, 2017-I-20, leg. Mingyi Tian \& Jingli Cheng.

Distribution. Guangxi (Fengshan) (Fig. 1). Known only from the cave Yuanyang Dong. 


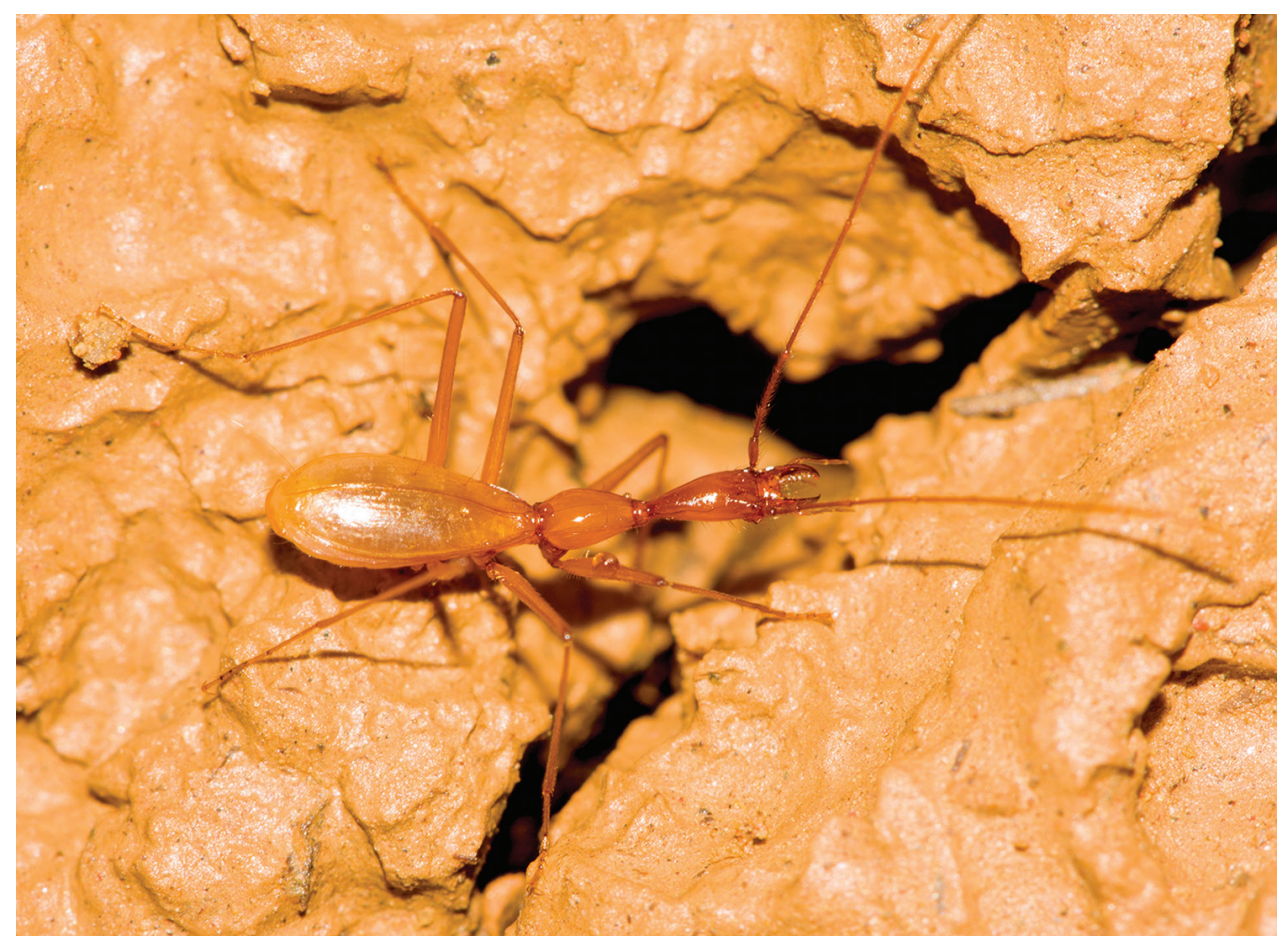

Figure 2. A living exemplar of Dongodytes (s. str.) fowleri Deuve, 1993.

Dongodytes (s. str.) tonywhitteni sp. n. http://zoobank.org/5E6380C9-E942-4360-AD80-DD09CC966956 Figs 1, 4, 5a, 6a, 7a, b

Material. Holotype: male, Guangxi: Hechi: Bama: Fenghuang: Dena: Cave Nonggong Dong, $24^{\circ} 11^{\prime} 26.28^{\prime \prime N} / 107^{\circ} 23^{\prime} 41.49^{\prime \prime E}, 439 \mathrm{~m}$ in altitude, 2015-VII-31, leg. Xinhui Wang, Mingruo Tang \& Jujian Chen leg., in SCAU; paratypes: 1 male and 2 females, ibid, in SCAU.

Diagnosis. Large cave beetles, eyeless and depigmented, with very elongated body and appendages, antennae extending beyond apices of elytra, fore part of the body longer than elytra, protarsomere I slightly denticulate inwards at apices in male.

Description. Length: 7.9-8.1 mm; width: 1.5-1.6 mm. Habitus as in Fig. 4.

Wholly reddish brown, with pale mouthparts palps and tarsi; slender and elongated body with very thin and long appendages, of which antennae evidently extending over apex of elytra. Smooth and glabrous on upper body surface but sparsely setose on head. Fore body longer (with mandibles) $((\mathrm{HLm}+\mathrm{PrL}) / \mathrm{EL}=1.12)$ or slightly shorter (excluding mandibles) $((\mathrm{HLl}+\mathrm{PrL}) / \mathrm{EL}=0.98)$ than elytra.

Head thin and very elongated, subconical but wider than that of both $D$. fowleri and $D$. grandis; much longer than wide, $\mathrm{HLm} / \mathrm{HW}=3.7, \mathrm{HL} / \mathrm{HW}=2.9 ;$ much longer than prothorax, $\mathrm{HLm} / \mathrm{PrL}=1.71, \mathrm{HL} / \mathrm{PrL}=1.35$; narrower than prothorax and pronotum, $\mathrm{HW} / \mathrm{PrW}=0.78, \mathrm{HW} / \mathrm{PnW}=0.94$; presence of two pairs of 


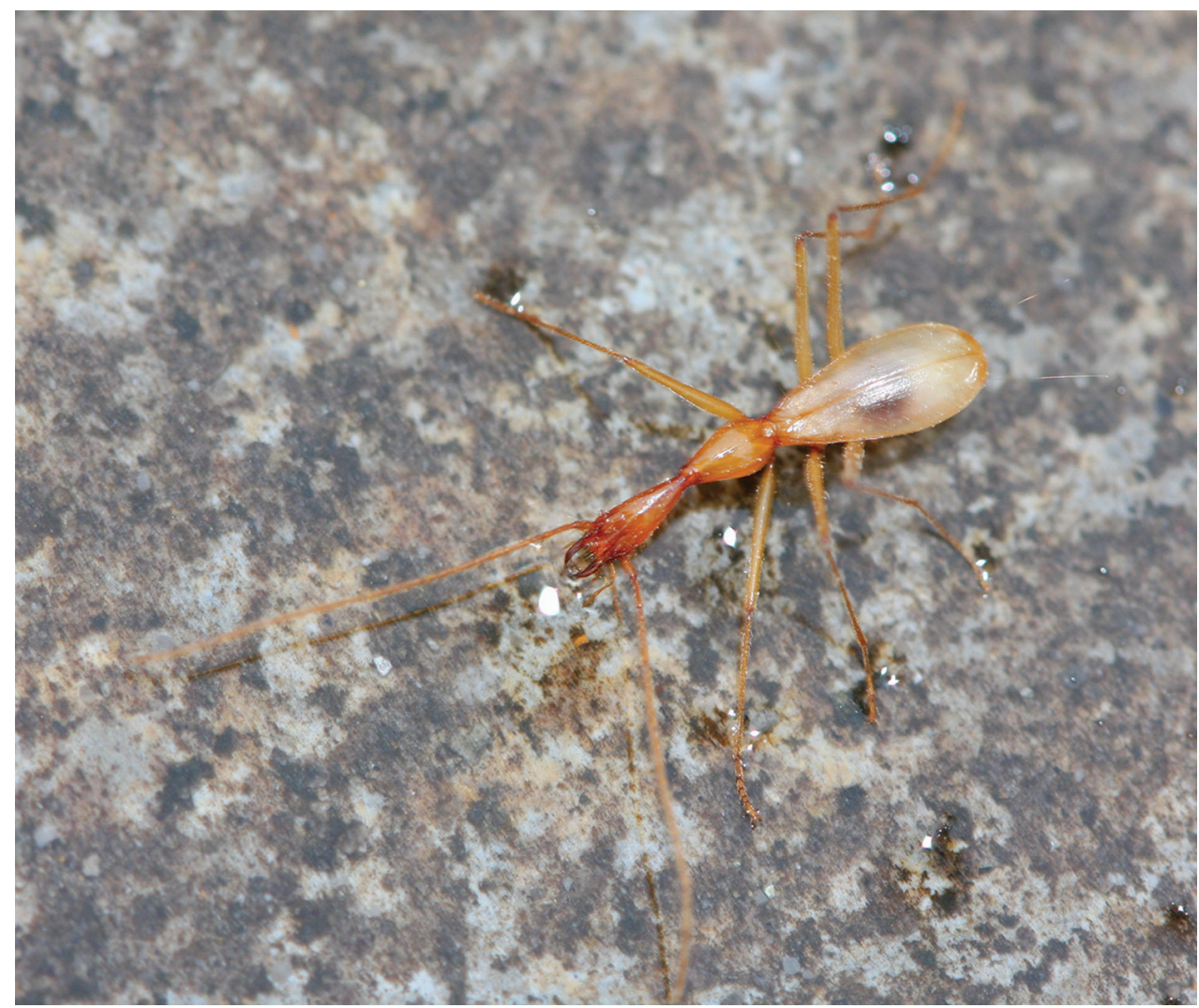

Figure 3. A living exemplar of Dongodytes (s. str.) grandis Uéno, 1998.

supraorbital pores, genae more widened than in both D. fowleri and D. grandis; labial suture traceable; mentum bisetose, concave basally; mentum tooth small and short, simple at tip; submentum 6-setose; palps very thin and slender; maxilla palpomeres III and IV glabrous; labial palp II bisetose on inner margin, 1.5 times longer than palp III which is glabrous; suborbital pores nearer neck than submentum. Antennae thin and very long, much longer than whole body including mandibles, extending over elytral apices from apical part of antennomere IX.

Prothorax elongated, shorter than head, 1.67 times longer than wide, evidently tumid on propleura, widest at approximately $1 / 3$ from base. Pronotum narrow and elongated, evidently wider than in both $D$. fowleri and $D$. grandis, twice as long as wide, PnL/PnW = 2.03; slightly wider than head, $\mathrm{PnW} / \mathrm{HW}=1.07$; base wider than front $(\mathrm{PbW} / \mathrm{PfW}=$ 1.6); widest at a little behind middle; lateral margins strongly sinuate before hind angles which are acute and sharp; anterior latero-marginal setae at approximately the apical $1 / 3$, basal ones before hind angles, at exactly the sinuated points. Scutellum small.

Elytra very elongated ovate, similar in both D. fowleri and D. grandis in shape and chaetotaxy, with well-marked lateral borders; $\mathrm{EL} / \mathrm{EW}=2.22, \mathrm{EL} / \mathrm{PnL}=2.42, \mathrm{EW} /$ $\mathrm{PnW}=1.82$. 


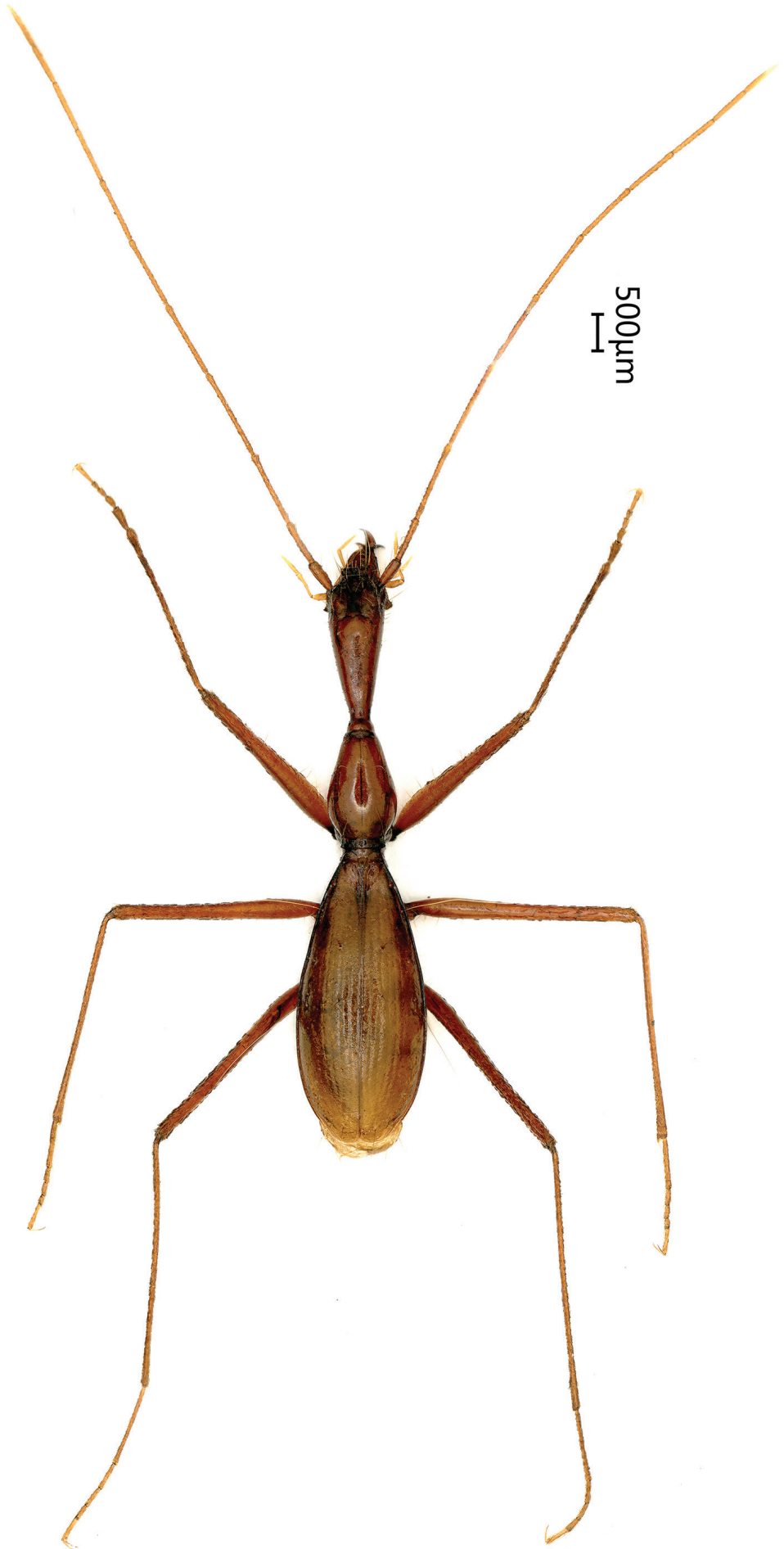

Figure 4. Habitus of Dongodytes (s. str.) tonywhitteni sp. n. 


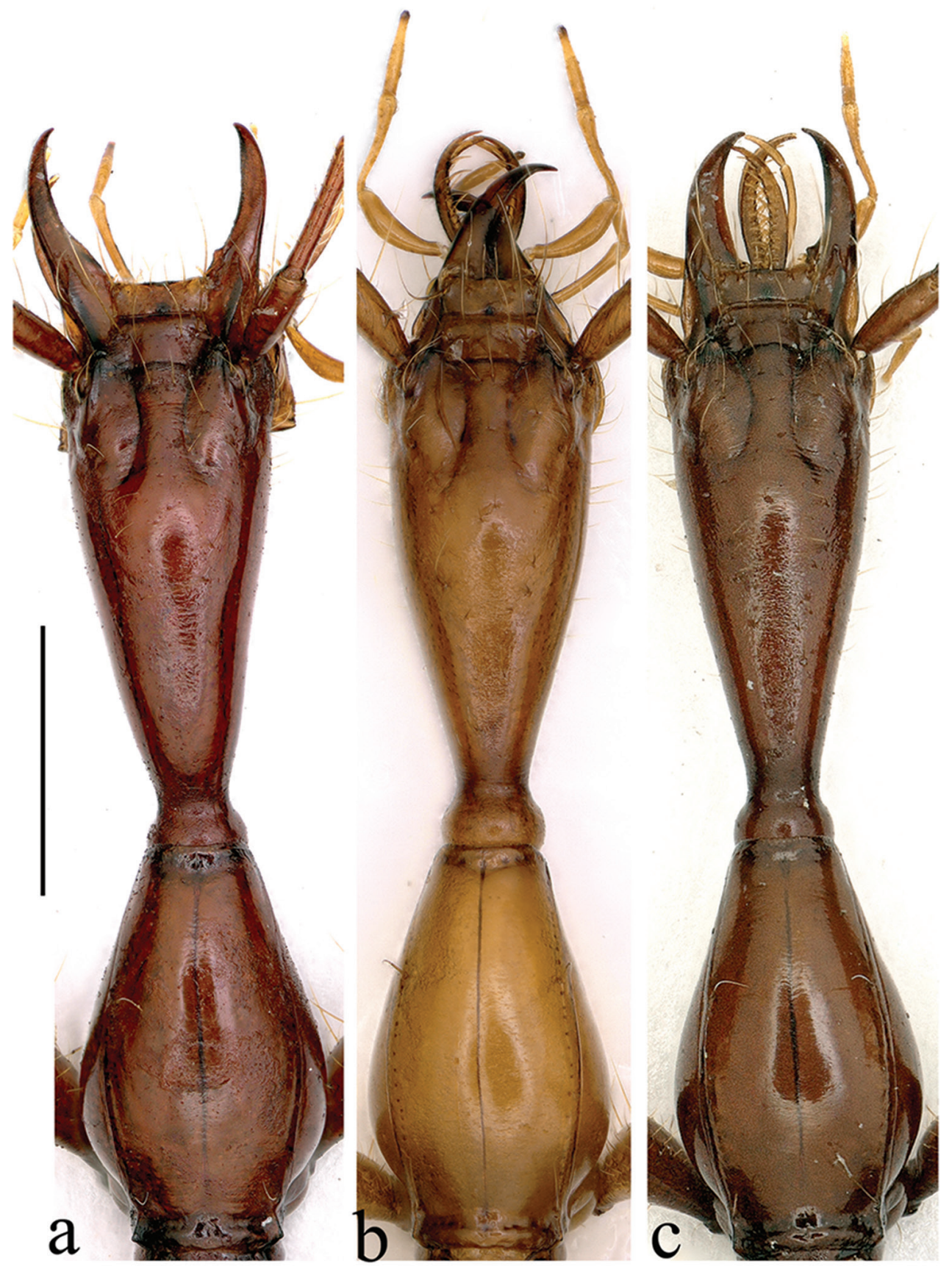

Figure 5. Head and pronotum of Dongodytes (s. str.) species a $D$. tonywhitteni sp. n. b $D$. fowleri c $D$. grandis. Scale bar: $1 \mathrm{~mm}$. 

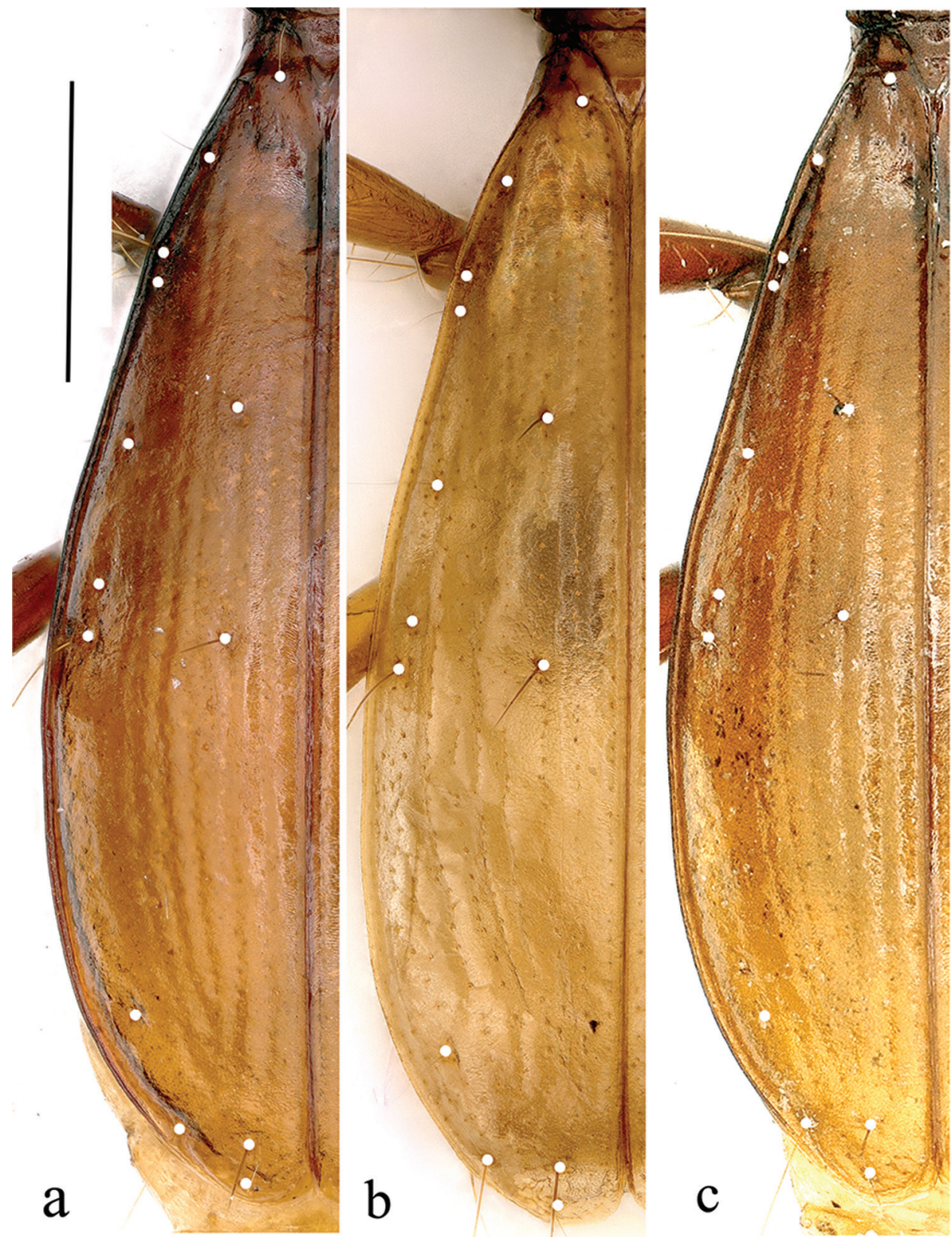

Figure 6. Left elytron of Dongodytes (s. str.) species, chaetotaxy shown by white points a $D$. tonywhitteni sp. n. b $D$. fowleri c $D$. grandis. Scale bar: $1 \mathrm{~mm}$. 

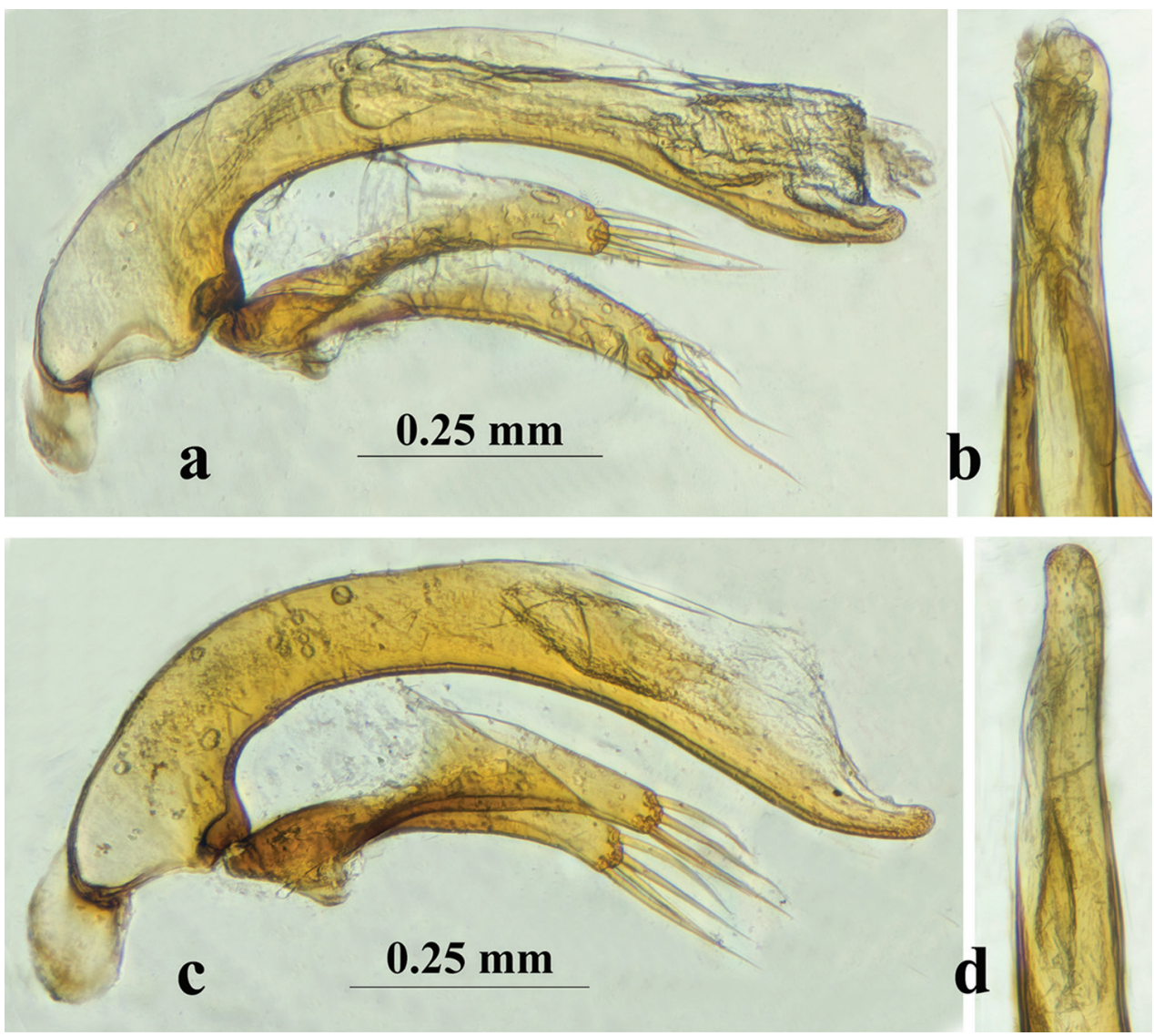

Figure 7. Male genitalia of Dongodytes (s. str.), median lobe and parameres (lateral view) and apical lobe (dorsal view) a, b D. tonywhitteni sp. n. c, d D. grandis.

Legs thin and very long, protibiae smooth, without longitudinal sulci, protarsomere I evidently longer than wide.

Ventrite IV-VI each with three pairs of paramedian setae; in female, IV and $\mathrm{V}$ each with a pair of setae, VI with two pairs in male; VII quadrisetose in female, bisetose in male.

Male genitalia (Fig. 7a, b): Aedeagus moderately sclerotized, median lobe similar to D. grandis Uéno, 1998 (Fig. 7c, d), but less curved ventrally, base a little stouter, with a smaller and narrower sagittal aileron, apex less reflexed, apical lobe wider, left paramere bearing four or five long setae at apex.

Remarks. Dongodytes tonywhitteni sp. $\mathrm{n}$. is closer to $D$. grandis than to $D$. fowleri Deuve, 1993 because both former two species have slenderer and longer aedeagus (Fig. 7), although Nonggong Dong cave is closer to Jiabao Dong or Xiaoshui Dong (the localities of $D$. fowleri Deuve, 1993) than to Yuanyang Dong (the locality of D. grandis Uéno, 1998) (Fig. 1). However, there are several differences in genital structures (mentioned above) between them. The striking morphological character of D. tonywhitteni sp. $\mathrm{n}$. is that lateral sides of pronotum is abruptly and strongly sinuate 
before the acute hind angles (Fig. 5a), versus gently sinuate before hind angles which are obtuse or more or less rectangular in both known species (Fig. 5b, c).

Etymology. The name of this new species is dedicated to the late Dr. Tony Whitten (Fauna \& Flora International, Cambridge, UK.), a famous biological conservationist in China and Southeast Asia who provided crucial support for cave biodiversity study in China.

Distribution. China (Guangxi: Bama County). Known only from the type locality, cave Nonggong Dong (Fig. 1).

The entrance of cave Nonggong Dong is largely opened and surrounded by bushes. Its length remains unknown. There is a large room near entrance, and it is very humid and muddy. An underground stream goes along the main passage which is very deep, and some parts of the cave are interrupted by vertical shafts. The trechine beetles were collected in dark areas ca. 10-30 metres away from the entrance. Other cave animals found also in this cave were millipedes, crickets, woodlice, and bats.

\section{Key to species of the subgenus Dongodytes (s. str.)}

1 Pronotum widened, lateral margins suddenly and deeply sinuate just before hind angles which are well-marked and acute (Fig. 5a).

D. (s. str.) tonywhitteni sp. n.

- $\quad$ Pronotum narrowed, lateral margins slightly sinuate before hind angles which are not well-marked and blunt (Fig. 5b, c) ................................................ 2

2 Protarsomere 4 stout, slightly longer than wide, lateral sides of pronotum invisible from above in apical fifth, hind angles of pronotum sharp

D. (s. str.) fowleri Deuve

- $\quad$ Protarsomere 4 slender, evidently longer than wide, lateral sides of pronotum invisible from above only near upper margin, hind angles of pronotum obtuse

D. (s. str.) grandis Uéno

\section{Acknowledgements}

We are very grateful to Prof. Achille Casale (Sassari University, Italy), Drs. Theirry Deuve and Arnaud Faille (the Paris Museum of Natural History, France) for their comments and suggestions which were helpful to improve the manuscript.

\section{References}

Deuve T (1993) Description de Dongodytes fowleri n. gen., sp. n., Coléoptère troglobie des karsts du Guangxi, Chine (Adephaga: Trechidae). Bulletin de la Société entomologique de France 98(3): 291-296. 
Tian MY (2011) A new subgenus and two new species of the troglobitic genus Dongodytes Deuve from Guangxi, China (Coleoptera, Carabidae). Subterranean Biology 8: 57-64. https://doi.org/10.3897/subtbiol.8.1232

Tian MY, Yin HM, Huang SB (2014) Du'an Karst of Guangxi: a kingdom of the cavernicolous genus Dongodytes Deuve (Coleoptera: Carabidae: Trechinae). ZooKeys 454: 69-107. https://doi.org/10.3897/zookeys.454.7269

Uéno SI (1998) Notes on Dongodytes (Coleoptera, Trechinae), with description of a new species. Journal of Speleological Society of Japan 23: 1-15.

Uéno SI (2005) A remarkably specialized new cave trechine (Coleoptera, Trechinae) from northern Guangxi, South China. Elytra 33(1): 333-339.

Uéno SI, Wang FX (1991) Discovery of a highly specialized cave trechine (Carabidae: Trechinae) in Southwest China. Elytra 19(1): 127-135. 